\title{
Cultura: um aporte contingencial
}

\author{
MYriam ÁviLA \\ Universidade Federal de Minas Gerais
}

\begin{abstract}
RESUMO: O INTERESSE DA IDÉIA DE CONTINGÊNCIA PARA A TEORIA É IMENSO, POIS AGE NO SENTIDO DE REFINAR, MODULAR E MALEABILIZAR PONTOS DE VISTA E ESCOPOS TOTALIZANTES, PERMITINDO UM MAIOR INFLUXO DOS DISCURSOS DO OUTRO E DAS CONFIGURAÇÕES DO PRESENTE NA ELABORAÇÃO TEÓRICA.UMA POSTURA ESPECULATIVA QUE PARTE DAS PRÓPRIAS APORIAS E APÓIA TODA POSSIBILIDADE DE SABER NA CURIOSIDADE SOBRE SEUS LIMITES É INFINITAMENTE MAIS FÉRTIL DO QUE AQUELA QUE REPOUSA CONFIANTE SOBRE PREMISSAS INDISCUTIDAS.

RESUMEN: EL INTERÉS DE LA IDEA DE CONTINGENCIA PARA LA TEORÍA ES INMENSO, PUES ACTÚA EN EL SENTIDO DE REFINAR, MODULAR Y MALEABILIZAR PUNTOS DE VISTA Y ESCOPOS TOTALIZANTES, PERMITIENDO INFLUJO MAYOR DE LOS DISCURSOS DEL OTRO Y DE LAS CONFIGURACIONES DEL PRESENTE EN LA ELABORACIÓN TEÓRICA. UNA POSTURA ESPECULATIVA QUE PARTE DE LAS MISMAS APORÍAS Y SOSTIENE TODA POSIBILIDAD DE SABER EN LA CURIOSIDAD SOBRE SUS LIIMITES ES INFINITAMENTE MÁS FÉRTIL QUE LA QUE REPOSA SEGURA SOBRE PREMISAS INDISCUTIDAS.
\end{abstract}

PALAVRAS-CHAVE: HOMI BHABHA, WALTER BENJAMIN, VERDADE, RELATIVISMO. PALABRAS-CLAVE: HOMI-BHABHA, WALTER BENJAMIN, VERDAD, RELATIVISMO. 
conceito de contingência é um dos mais interessantes operadores postos em movimento por Homi K. Bhabha em seu livro O local da cultura. O termo, que atravessa toda a história da filosofia, adquiriu grande destaque nos estudos pós-colonialistas e constitui uma das bases da argumentação do teórico indiano. De inspiração - parece-me - benjaminiana (a referência seriam as teses sobre o conceito de história), a contingência em Bhabha tem um caráter basicamente antitotalizante e antiuniversalista. Contemplaria os avessos e as costuras da história, através da interpelação "incomensurável" (o termo é de Bhabha) das narrativas que a constituem. $\mathrm{Na}$ formulação de Benjamin, datada de 1940, ${ }^{1}$ trata-se da "imagem do passado", da "verdadeira imagem histórica" que "se apresenta, no momento do perigo, ao sujeito histórico, sem que ele tenha consciência disso" (grifo meu). Benjamin usa repetidamente a palavra "momento" e o verbo "relampejar" com relação a essa imagem e propõe que a construção da história se dê em um "tempo saturado de 'agoras". A imagem que relampeja no agora nos permitiria, segundo Benjamin, "perceber que nossa tarefa é originar um verdadeiro estado de exceção".

Bhabha retoma a visão benjaminiana em tom mais argumentativo, associando os "relâmpagos" que irrompem no tempo homogêneo do vencedor à enunciação inesperada - incomensurável - do subalterno, onde antes soava o discurso do dominador. A partir da afirmação de que a perspectiva pós-colonial resiste à busca de formas holísticas de explicação, ${ }^{2}$ Bhabha propõe lidar com a cultura como produção irregular e incompleta ${ }^{3}$ de sentido e valor. Vista assim, toda agência é uma atividade do contingente e o agente passa a ser uma forma de retroatividade, Nachträglichkeeit (258), não mais o autor ou o sujeito de um "efeito" coletivo e sim algo que está se construindo na prática da ação, como na colocação de Franz Fanon. ${ }^{4}$ Responsável embora por momentos de fechamento ou conclusão, a agência contingente não apresenta, entretanto,

\footnotetext{
${ }^{1}$ Citado aqui a partir da edição brasileira, com tradução de Sérgio Rouanet.

${ }^{2}$ BHABHA, Homi K. O local da cultura. Trad. Myriam Ávila, Eliana L. L. Reis e Gláucia R.Gonçalves. Belo Horizonte: Ed. UFMG, 1998. p. 241.

${ }^{3}$ Id. Ibid. p. 240.

${ }^{4}$ FANON, Franz. The wretched of the earth. Apud: BHABHA, Homi K. O local da cultura.Trad. Myriam Ávila, Eliana L. L. Reis e Gláucia R.Gonçalves. Belo Horizonte: Ed. UFMG, 1998. p. 269.
} 
teleologia. Seus significados, signos e não símbolos, nascem da negociação momentaneamente necessária e só podem ser estabelecidos a posteriori.

Bhabha distingue dois modos de contingencialidade: contingência como contigüidade e contingência como indeterminação. No primeiro caso temos a ausência de causalidade, seqüencialidade e subordinação: prevalece a posição com, a simultaneidade, a proximidade. No segundo, a falta de determinação e teleologia, o indecidível.

Assim resumida e pinçada da estrutura curvilínea de sua argumentação em O local da cultura, a proposta de Bhabha deixa entrever um aspecto aporético de sua teoria. Se às considerações acima acrescermos o desejo expresso pelo teórico, no capítulo IX, de substituir à epistemologia a enunciação ("passagem do cultural como objeto epistemológico à cultura como lugar enunciativo"), ${ }^{5}$ teremos o paradoxo de uma teoria que não pretende ser uma via para o conhecimento, quando o termo é definido filologicamente como "conhecimento especulativo", "sistema de proposições", "regras e princípios gerais". Ao postular a impropriedade de buscar conhecer diante de um cenário marcado pela contingência e a impossibilidade de tomar as medidas do incomensurável, ao atribuir à ação um saber não discursivo, cego e indecidível antes de sua conclusão, o teórico indiano condena a atividade especulativa à mera contemplação (no que se aproxima do sentido etimológico de theoria, do grego theasthai, observar).

Bhabha sugere que se aborde a questão da teoria de um ponto de vista lingǘstico. $\mathrm{O}$ correlato da teoria da contingência seria a construção de frases "fora da sentença" ou, para nossos propósitos, do sentencial. A resistência às formas totalizantes da sintaxe, ${ }^{6}$ principalmente através de recursos como a cesura e a catacrese, corresponderia à resistência a categorias interpretativas totalizantes, como o sujeito prévio ao discurso, por exemplo. É importante notar que não se apela para figuras de linguagem, como a metáfora e a metonímia, mas a recursos de construção da frase. A aporia aqui reside no fato de que o texto teórico só pode usar com muita parcimônia tais recursos. Mesmo dentro de uma concepção ensaística do discurso metalin-

${ }^{6}$ Já discutida de forma interessantíssima no ensaio Parataxe, de Theodor W. Adorno. 
güístico, a exceção tem de permanecer exceção ${ }^{7}$ e só se impõe por oposição à norma. Se Benjamin nos conclama a "originar um verdadeiro estado de exceção", só podemos pensá-lo como horizonte que permanece horizonte, nunca como prática diária (o que seria uma contradição em termos).

Deixemos de lado por enquanto esse ponto e voltemo-nos para o conceito de cultura. Pensar a cultura no âmbito da contingência exige abandonar "O conceito de cultura enquanto totalidade de conteúdos canônicos"8 Bhabha define sua visão da cultura como "a produção desigual e incompleta de significação e valores, muitas vezes resultantes de demandas e práticas incomensuráveis, produzidas no ato de sobrevivência cultural". ' Parece-me que já há algum tempo estamos todos, como intelectuais e teóricos, dispostos a aceitar essa concepção ampla e aberta, mas, na prática, teríamos mais facilidade em vivê-la no contexto cultural em que nos encontramos imersos do que quando observamos, de segura distância, a cultura do Outro. Aí, a tendência irresistível é pensá-la como um bloco fechado e resistente à negociação, principalmente pela identificação de cultura com espaço nacional. O projeto de Bhabha pede um descolamento das duas noções, substituindo ou suplementando a determinação geopolítica com uma série de posições possíveis do sujeito, como raça, gênero, geração, orientação sexual, etc., sem esquecer as diversas vinculações que se estabelecem em pequenos núcleos, profissionais, institucionais e locais.

Rodrigo Duarte enumera ${ }^{10}$ quatro conceitos de cultura: o geral (tudo o que a humanidade faz é cultura, por oposição a natureza); o específico (por oposição a civilização); o restrito (correspondendo ao que se denomina "alta cultura") e o "operacional" (cultura como software humano). Os três primeiros,

\footnotetext{
${ }^{7}$ Lembro aqui os comentários de Barthes sobre a frase, em O prazer do texto, no qual a parataxe e a cesura não são suficientes para atirar o texto para "fora da frase". Bhabha baseia sua proposta nessa passagem de Barthes.

${ }^{8}$ SOUZA, Lynn Mario T. Menezes de. "Hibridismo e tradução cultural em Bhabha". ABDALA JR, Benjamin (org.). Margens da cultura. Mestiçagem, bibridismo \& outras misturas. São Paulo: Boitempo, 2004. p. 125.

${ }^{9}$ SOUZA, Lynn Mario T. Menezes de. Op. Cit.

${ }^{10}$ Em texto inédito, ainda em elaboração, gentilmente cedido à autora.
} 
por seu caráter abrangente, só admitem o uso do termo no singular. O último corresponde à diversidade subentendida no plural "culturas".

Para tornar claras as funções que a cultura, em sua acepção plural, adquire como objeto teórico e discursivo em um panorama de medialização e comercialização das trocas simbólicas, creio ser produtivo partir de uma definição "minimamente operacional" de cultura, como a que propus há alguns anos em um curto ensaio: "o conjunto dos bens de identificação de um grupo dado, podendo esse grupo variar enormemente em amplitude, indo desde uma pequena comunidade geograficamente determinada até todo um gênero, como as mulheres". ${ }^{11}$ Esta definição tem a vantagem de ser maleável às mudanças no interior do conjunto, pois qualquer elemento que em um determinado ponto não esteja de fato servindo como bem de identificação pode ser imediatamente descartado, enquanto novos elementos podem ser introduzidos conforme sejam ativados pelo grupo. Além disso, não pressupõe a identificação com uma única cultura, mas, ao contrário, torna reconhecido o grupo como uma cultura desde que haja bens de identificação que o distingam. Uma cultura deixa de existir se seus bens de identificação não estiverem sendo ativados por um grupo de indivíduos. As culturas mortas só podem ser então acionadas no discurso como "totalidade de conteúdos canônicos". Despojos destes, porém, podem ser apropriados pelos imaginários de novas culturas.

O conceito operacional de cultura acima estaria, portanto, aberto à contingência. A contingência pela contigüidade, de que fala Homi Bhabha, é prevista pela possibilidade que se abre às diversas culturas de se apropriarem de bens de identificação de outras ou de produzirem um determinado bem de identificação cuja relevância e adequação o leve a ser adotado por uma cultu$r a$ de âmbito mais abrangente. $\mathrm{O}$ trânsito atual entre culturas favorece a mobilidade e mutabilidade das identificações, trazendo-nos a visão feliz de um mundo em constante hibridização. No entanto, como esses contatos entre grupos culturais se dão em um mundo bombardeado por informações que, apesar de multidirecionais, têm origem em uns poucos centros de pro-

\footnotetext{
${ }^{11}$ ÁVILA, Myriam. "Héctor Libertella: um passeio pelos limites da cultura “. OTTE, Georg e OLIVEIRA, Silvana Pessôa de. Mosaico crítico. Ensaios sobre literatura contemporânea. Belo Horizonte: Autêntica, 1999. p. 75.
} 
dução de bens simbólicos, há uma tendência crescente de identificação com esses bens globalizados, selecionados e esquematizados extrinsecamente por agências de comunicação. Teóricos como Bhabha e Canclini adotam a postura otimista de que mesmo a informação pasteurizada, ao ser absorvida por uma cultura periférica, é refratada idiossincraticamente e re-emitida em clave híbrida, em um processo que já foi denominado rasquachismo - em bom brasileiro, gambiarra.

Benjamin Abdala Jr. é mais cauteloso na avaliação dos movimentos transculturais na contemporaneidade. A par da flexibilização das fronteiras e produção híbrida de significações, Abdala ${ }^{12}$ aponta para a permanência do capital como instância última de poder, a pasteurização da diferença pela indústria cultural e o recrudescimento das estratégias imperialistas sob o atual governo Bush. Carlo Ginzburg, por sua vez, chama a atenção para os perigos do relativismo, que é o corolário natural da suspensão dos valores universalistas:

Hoje, num tempo no qual a convivência, não raro conflituosa, entre culturas diversas se transferiu para as metrópoles, ouve-se cada vez mais a afirmação de que os princípios morais e cognitivos das várias culturas não podem ser objeto de comparação. Essa atitude que, em teoria, deveria desembocar numa tolerância ilimitada provém paradoxalmente de uma premissa similar ao princípio que faz coincidir a justiça com o direito do mais forte. ${ }^{13}$

Em outras palavras, onde as razões de todos são igualmente válidas, provavelmente predominará a força como vetor principal das mudanças. Se prevalece a crise de legitimação dos valores universais, em nome de quê condenar os atentados de 11 de setembro nos Estados Unidos? Ginzburg não menciona esse fato, mas chama a atenção para "o risco de fragmentar o conhecimento (e a vida social) numa série de pontos de vista incomunicáveis, nos quais cada grupo se vê murado no interior da sua própria relação com o mundo" (p.39) A abordagem da convivência entre culturas diversas via tradu-

\footnotetext{
${ }^{12}$ ABDALA JÚNIOR, Benjamin. "Um ensaio de abertura: mestiçagem e hibridismo, globalização e Comunitarismos". _ _ (org.). Margens da cultura. Mestiçagem, hibridismo \& outras misturas. São Paulo: Boitempo, 2004. p. 9-20.

${ }^{13}$ GINZBURG, Carlo. Relações de força. História, retórica, prova. Trad. Jônatas B. Neto. São Paulo: Companhia das Letras, 2002. p. 15.
} 
ção, "crítica e delimitada", como a quer Donna Haraway, ${ }^{14}$ não lhe parece suficiente, uma vez que "os instrumentos que nos permitem compreender culturas diversas da nossa são os instrumentos que nos permitiram dominá-las". ${ }^{15}$

A meu ver, Ginzburg não incorre na censura de Bhabha aos historiadores que, em "narrativa continuística", deixam de lado os "lugares e símbolos contraditórios e híbridos" da história. As incursões do historiador italiano não me parecem negar "a agência como atividade do contingente", ${ }^{16}$ mas veriam, ainda no contingente, a confirmação de relações de força prevalentes no mundo de forma global. Se o contingente mostra-se eficaz no solapamento do logo(etno)centrismo ocidental, o que deixa em seu lugar é a imersão no puro devir, cuja "inocência", postulada por Nietzsche, ${ }^{17}$ redundaria em vontade de poder. $\mathrm{O}$ mundo da pura contingência seria impossível por sua precariedade; a indeterminação preclui, no limite, a atividade teórica, e o discurso, eleito única medida das relações sociais, corre o risco de, ou ser atropelado pela realidade empírica, ou ver-se - horrorizado como o Kurz de Conrad - cristalizar monstruosamente em realidade, como no já citado 11 de setembro. A questão vem sendo objeto de polêmica entre os estudiosos da cultura, um dos quais sentencia: "A pura contingência, a incomensurabilidade ou a fragmentação não se prestam senão a uma especificação ad hoc". ${ }^{18}$

Entretanto, o interesse da idéia de contingência para a teoria é imenso, pois age no sentido de refinar, modular e maleabilizar pontos de vista e escopos totalizantes, permitindo um maior influxo dos discursos do Outro e das configurações do presente na elaboração teórica.Uma postura especulativa que parte das próprias aporias e apóia toda possibilidade de saber na curiosidade sobre seus limites é infinitamente mais fértil do que aquela que repousa confiante sobre premissas indiscutidas.

\footnotetext{
${ }^{14}$ Citada por Ginzburg, p.39.

${ }^{15}$ GINZBURG, Carlo. Relações de força. História, retórica, prova. Trad. Jônatas B. Neto. São Paulo: Companhia das Letras, 2002. p. 43.

${ }^{16}$ BHABHA, Homi K. O local da cultura. Trad. Myriam Ávila, Eliana L. L. Reis e Gláucia R.Gonçalves. Belo Horizonte: Ed. UFMG, 1998. p. 260.

${ }^{17}$ Estamos ainda aqui seguindo a argumentação de Ginzburg, que toma o termo "inocência do devir", atribuído a Nietzsche, em A escritura e a diferença, de Derrida. (Cf. Ginzburg, p.36)

${ }^{18}$ HALLWARD, Peter. "The singular and the specific: recent French philosophy". p. 2.

http://www.radicalphilosophy.com/print.asp?editorial_id=10088
} 
Grande interesse parece-me ter ainda a agência contingente que se expressa em formulações verbais ou não de maneira inesperada e indecidível. Muitas das melhores especulações críticas da teoria contemporânea partem de momentos contingentes de textos e imagens alheios, que, para usar o termo de Walter Benjamin, relampejam no interior de um discurso aparentemente controlado. O próprio Homi Bhabha identifica um desses momentos em Foucault, e o utiliza para ilustrar sua abordagem da questão da agência. ${ }^{19}$ Foucault é levado por sua própria argumentação a se confrontar com a agência pós-colonial e embora se recuse a admitir sua relevância como interpelação da razão ocidental, esse momento abre uma clivagem no discurso, "um outro lugar de enunciação que não permitirá à argumentação se expandir em uma generalidade não-problemática". ${ }^{20}$

A produtividade intertextual desses momentos de contingência é imensa e não se restringe ao seu rastreamento em textos teóricos. Muitas vezes são textos literários, melhor dizendo, retalhos de textos literários que provocam iluminadoras reflexões por parte de seus leitores-escritores. Carlo Ginzburg escreve, em Relações de força, todo um capítulo ("Decifrar um espaço em branco") a partir de uma observação de Proust a respeito de Flaubert: "Na minha opinião, a coisa mais bela da Educação sentimental não é uma frase mas sim um espaço em branco". É conhecido como Derrida e outros pós-estruturalistas derivam textos inteiros de curtas formulações verbais de diversas origens, a que emprestam um caráter catacrésico. (Um belo exemplo é "Donner le temps", de Derrida).

Outras vezes, basta retirar um texto de seu contexto habitual para que ele mostre seu caráter incisivamente contingente e exerça uma interpelação crítica de seu entorno. Interessam-me especificamente aqueles textos produzidos de forma (quase) anônima e primitiva, não nascidos de um olhar crítico armado, mas do olhar distraído do flâneur que, como no Blow up de Antonioni, capta o instante de um crime que é também a radiografia de uma conjuntura histórica. Por estranha que pareça a conexão entre a especificidade do crime

${ }^{19}$ BHABHA, Homi K. O local da cultura. Trad. Myriam Ávila, Eliana L. L. Reis e Gláucia R.Gonçalves. Belo Horizonte: Ed. UFMG, 1998. p. 270.

${ }^{20}$ Id. Ibid. p. 272. 
e a abrangência da conjuntura histórica, a conjunção crime/história é suficientemente clara a ponto de poder fazer do episódico uma alegoria do malestar de uma época. Assim, toda radiografia do nosso tempo será a fotografia de um crime. ${ }^{21}$

As imagens de que fala Walter Benjamin, aquelas que relampejam no momento de perigo, são também instantâneos, flashes, impressões de luz sobre a retina. Nota-se, porém, uma diferença destas com relação às irrupções do contingente na teoria de Bhabha: elas seriam imagens verdadeiras e se apresentariam "no momento do perigo". Se em Bhabha tais irrupções teriam o papel político e crítico de fraturar o tempo homogêneo do dominador, não chegam, entretanto, a ter o peso da revelação nem o caráter de resgate de uma situação perigosa. Sua ação seria mais insidiosa e desconstrutora, voltada contra a lógica da dominação. Daí talvez o cuidado de não vinculá-la a um conteúdo de verdade, como o faz Benjamin, que no entanto faz questão de separar verdade de conhecimento. Seria impossível, para o filósofo frankfurtiano, "saber" a verdade. O saber histórico é relativo, mas a verdade deve ser absoluta. Deste modo, só se poderia conceber a última "do ponto de vista da história como totalidade plena". 22

Portanto, ao falar da imagem verdadeira que explode o tempo vazio e homogêneo no momento do perigo, Walter Benjamin propõe uma ligação entre verdade e contingência. A verdade não seria uma construção do conhecimento, mas um insight independente de qualquer intenção: "sem que ele [o sujeito histórico] tenha consciência disso". ${ }^{23}$ Cria-se, assim, um horizonte de plenitude para a história, em uma "exterioridade além do tempo", e não projetado "para um tempo histórico posterior", ${ }^{24}$ como na utopia. O importante aqui é que a contingência não faz sentido, ou não interessa, sem essa ancoragem em uma verdade incomensurável por um lado, mas inexorável por outro.

\footnotetext{
${ }^{21}$ Ver, a respeito, o filme Nossa música, de Jean Luc Godard.

22 OSBORNE, Peter. "Signo, imagem e metafísica". Hand-out para a semiplenária

Usos de Benjamin. Anais do $6^{\circ}$ Congresso da ABRALIC. Florianópolis: 18-22 ago 1998. p. 1.

${ }^{23}$ BENJAMIN, Walter. Obras escolbidas. Magia e técnica, arte e política. Trad. Sérgio P. Rouanet. São Paulo: Brasiliense, 1994. p. 224.

${ }^{24}$ OSBORNE, Peter. "Signo, imagem e metafísica". Hand-out para a semiplenária Usos de Benjamin. Anais do $6^{\circ}$ Congresso da ABRALIC. Florianópolis: 18-22 ago 1998.
} 
Carlo Ginzburg também traz à baila a discussão sobre a verdade. Em seu caso, porém, esta não representa um insight repentino acionado por uma agência contingente. $\mathrm{O}$ historiador insiste na existência e na relevância de provas que podem apontar para fatos exteriores ao discurso e instituir um parâmetro de avaliação caso a caso, onde o relativismo só via a incomensurabilidade das culturas, umas com relação às outras. Seja como for, em Benjamin ou em Ginzburg, existe algo que vai além das diferenças e da diversidade, e que até garante que essas não se mesclem num pluralismo homogeneizante: a verdade, que no momento do perigo - perigo para todos - irrompe como imagem ou como prova. A força com que se impõe contingencialmente em qualquer dessas formas à consciência daqueles que dela não tinham consciência garante sua validade. Não só sua incisiva validade no momento em que brilha, mas a sua validade como idéia, como baliza.

Quando Kurz grita “o horror, o horror", ele cria um momento de verdade que corrói a ordem e a lógica da casa da pretendida e de seu entorno protegido. Da mesma forma a "shoah" (catástrofe, destruição), o extermínio dos judeus pelos nazistas, corrói - diz Adorno - toda a poesia ocidental.

Porém, embora a verdade seja absoluta em seu relampejo, ela só pode ser entrevista através desse, através da contingência que a cristaliza em prova ou imagem. Postulada, sabida ou conhecida, ela é apenas uma verdade entre muitas, restrita ao seu espaço relativo de consenso. Desejada, feita promessa, ela se mostra enfim plena: não uma verdade qualquer, mas a verdade verdadeira. Uma das mais interessantes formulações desse desejo pela verdade que salva e da simultânea compreensão das diversas verdades localizadas que não anulam nem a primeira nem umas às outras está na canção "Falar a verdade", da banda Cidade Negra. ${ }^{25}$ Esta banda, que tem um repertório fraco de canções no ritmo reggae, nos dá um bom exemplo de agente não intencional, já que sua canção nasce de forma espontânea e pouco consciente, em uma tentativa pouco elaborada de seguir a tradição de protesto do reggae jamaicano. Provocativa nela é a firmeza com que se afirma a existência da "verdadeira verdade" e a firmeza com que se promete revelá-la.

\footnotetext{
${ }^{25}$ A composição é de autoria da banda Cidade Negra como um todo.
} 
Entretanto, nada no cenário descrito faz crer na possibilidade próxima de cumprimento da promessa, já que seus próprios emissores não a conhecem, mas apenas estão curiosos por conhecê-la. Quando chegarem a conhecê-la, prometem não guardá-la para si, e sim levá-la a:

$[\ldots]$ você que nasce

você que cresce

você que luta para se manter

você que pede pra sobreviver [...]

$[\ldots]$ você que anda no meio da rua

você que lê livro de mulher nua

você que vê coisa invisível

você que crê no todo-poderoso [...]

[...] você que foge como um ladrão

tentando se esquivar da perseguição [...]

[...] você que olha com toda a curiosidade

a fim de saber a verdadeira verdade

Cada interlocutor é evocado em sua particularidade, em sua diferença. Não há tentativa de homogeneização. Cada um tem a sua verdade, representa um segmento, não de forma essencialista e sim contingencial. Nenhum porta uma identidade fixa e imutável e sim identificações que o reportam a esse ou aquele grupo. Porém, os dois primeiros grupos, o dos que nascem e dos que crescem, têm abrangência universal. Todos, necessariamente, pertencem a essas duas classes. A canção sugere também que todos podem pertencer à classe dos que "olham com toda a curiosidade" e que é a esses, de fato, que a promessa se dirige. Se a contingência física une todos os "vocês", seria desejável que a curiosidade também os unisse. A identificação pela abertura (ao que quer se apresente a uma mente curiosa) em lugar de pelo fechamento (em uma identidade fixa) permite postular uma universalidade que não se pauta pelo já estabelecido.

Nos termos da presente discussão: não se trata de voltar à figura do "homem" universal que se sobrepõe ao homem historicizado, mas de lembrar a existência real de "você" - contextualizado, contingente, marcado pela diferença e passível de ser interpelado. A figura que ressalta na canção é a do 
subalterno e a situação em que o interpelado se encontra é de sobrevivência. Há, entretanto, uma sugestão, ou suspeita, de que reina um estado geral de subalternidade na comunidade dos vivos. Poder-se-ia propor também que essa subalternidade decorre da supressão da verdade como valor: a tabula rasa dos valores, que transforma a "plena humanidade" em apenas um grand récit de legitimação esgotada, esvazia a busca pelo "mundo reconciliado". ${ }^{26}$ Mas não diz a música - a aspiração por ele por parte do subalterno que, interpelado, faz do atraso na resposta (belatedness, em Bhabha) o próprio espaço do desejo.

Ouve-se, mesmo imiscuído nos produtos da indústria cultural, esse desejo. Pode-se contar com ele para que a relativização dos pontos de vista não implique "de nenhum modo, a tolerância contente de qualquer opinião que se queira manter". ${ }^{27} \mathrm{O}$ esforço de autocorreção e a recusa a desviar-se dos obstáculos colocados por um pensamento complexo ${ }^{28}$ são uma imposição ética que se coloca ao trabalho teórico, aquém tanto das posições pré-assumidas quanto do deleite no discurso.

\section{Referências bibliográficas}

ABDALA JÚNIOR, Benjamin. "Um ensaio de abertura: mestiçagem e hibridismo, globalização e Comunitarismos". . (org.). Margens da cultura. Mestiçagem, hibridismo \& outras misturas. São Paulo: Boitempo, 2004.

ÁVILA, Myriam. "Héctor Libertella: um passeio pelos limites da cultura". OTTE, Georg e OLIVEIRA, Silvana Pessôa de. Mosaico crítico. Ensaios sobre literatura contemporânea. Belo Horizonte: Autêntica, 1999.

BENJAMIN, Walter. Obras escolbidas. Magia e técnica, arte e política. Trad. Sérgio P. Rouanet. São Paulo: Brasiliense, 1994.

BHABHA, Homi K. O local da cultura. Trad. Myriam Ávila, Eliana L. L. Reis e Gláucia R.Gonçalves. Belo Horizonte: Ed. UFMG, 1998.

CANCLINI, Néstor García. Consumidores e Cidadãos. Conflitos multiculturais da globalização. Rio de Janeiro: UFRJ, 1995.

\footnotetext{
${ }^{26}$ Termo de Theodor Adorno.

${ }^{27}$ PERKINS, David. Is literary history possible? Baltimore/Londres: The Johns Hopkins University Press, 1993.

${ }^{28}$ Derrida invoca para si essa recusa e esse esforço, em entrevista na TV, no Brasil, pouco antes de sua morte.
} 
COUTURE, Barbara. "Against relativism: restoring truth in writing". http:// jac.gsu.edu/jac/13.1/Articles/7.htm. (1993)

GINZBURG, Carlo. Relações de força. História, retórica, prova. Trad. Jônatas B. Neto. São Paulo: Companhia das Letras, 2002.

HALLWARD, Peter. "The singular and the specific: recent French philosophy". http:/ / www.radicalphilosophy.com/print.asp?editorial_id=10088

OSBORNE, Peter. "Signo, imagem e metafísica". Hand-out para a semiplenária Usos de Benjamin. Anais do $6^{\circ}$ Congresso da ABRALIC. Florianópolis: 18-22 ago 1998.

PERKINS, David. Is literary history possible? Baltimore/Londres: The Johns Hopkins University Press, 1993.

SOUZA, Lynn Mario T. Menezes de. "Hibridismo e tradução cultural em Bhabha". In: ABDALA JR, Benjamin (org.). Margens da cultura. Mesticagem, hibridismo \&o outras misturas. São Paulo: Boitempo, 2004. 